\title{
Sobre el concepto de apropiación de Chartier y las nuevas prácticas culturales de lectura (el fan fiction)'
}

On Chartier's concept of appropriation and new cultural practices of reading (fan fiction) ${ }^{\prime}$

\author{
ALBERTO E. MARTOS GARCÍA \\ Universidad de Extremadura \\ España \\ aemargar@gmail.com
}

Resumen. La cultura letrada clásica concebía como la lectura como una práctica superior circunscrita a círculos cultivados. La cultura digital ha extendido la lectura como práctica popular. Se analiza a este respecto el concepto de apropiación de Chartier y sus implicaciones culturales y educativas, en particular, el fan fiction y otros fenómenos concomitantes. Se debe alentar una alfabetización integral, no sólo tecnológica, hacia las nuevas prácticas de lectura, que hagan posible la apropiación en los diferentes niveles, cultura letrada, cultura mediática y cibercultura.

Palabras clave: cultura letrada, cultura digital, lectura, apropiación, fan fiction.
Abstract. The educated classes used to conceive reading as a superior practice limited to cultivated circles. Digital culture has spread reading as a popular practice. We analyze digital culture using the concept of appropriation and its cultural and educational implications, in particular, fan fiction and related phenomena. Literacy should be encouraged as integrated practice, not limited to technology, making appropriation possible at different levels; literate culture, media culture and cyberculture.

Key words: Written Culture, digital culture, reading, appropriation, fan fiction

\footnotetext{
${ }^{\text {I }}$ Para citar este artículo: Martos García, A., Sobre el concepto de apropiación de Chartier y las nuevas prácticas culturales de lectura (el fan fiction). Alabe 4, diciembre 2OII [http://www.ual.es/alabe]
} 
"La apropiación tal como la entendemos nosotros apunta a una historia social de usos

e interpretaciones, relacionados con sus determinaciones fundamentales e inscritos en las prácticas específicas que los producen" Roger Chartier. Elmundo como representación

\section{INTRODUCCIÓN}

A menudo el concepto de "lectura apropiada" se maneja desde unas coordenadas morales o de psicología, como cuando se habla de "elegir textos apropiados a la edad del niño", valorando, pues, que conecten con sus intereses y se ajusten a su nivel evolutivo. Sin embargo, como trataremos de argumentar, los enfoques de R. Chartier (I985) giran más en torno a la lectura como construcción de sentido, esto es, como apropiación, que afecta a los objetos culturales en sentido amplio, no sólo los libros, que sufren procesos de ser producidos, transmitidos y "apropiados" en determinadas comunidades. Además, la construcción del sentido no es algo que se haga desde la privacidad o el aislamiento, subyace a ella las prácticas de lectura socialmente instauradas, de ahí el enfoque histórico de la cuestión.

Otra cosa muy distinta es este enfoque moralista que se entiende por "lectura (in) apropiada", el cual nos lleva por ejemplo al concepto de lectura "adecuada", "lectura por edades", tema a veces controvertido, que no es el objeto de este artículo pues sí un referente a considerar. Es sabido que igual que es cierto que la edad condiciona sin duda la recepción del texto, también es verdad que no todos los niños de una misma edad tienen el mismo grado de desarrollo ni el mismo entorno ni han adquirido el mismo intertexto (Mendoza 2003). Así pues, salvando todos los matices que se puedan exponer al respecto, cabe destacar que la idea de orientar las lecturas y de adecuarlas a una finalidad tiene un origen sociohistórico ya estudiado por especialistas (Chartier 1994), normalmente, el de la inculcación con algún propósito, normalmente moralizante o adoctrinador. Es algo que la historia y la sociología de la lectura han puesto sobradamente de evidencia.

En todo caso, a menudo se suelen describir, por un lado, los parámetros de los llamados estadios de desarrollo del niño, y por el otro, las propiedades formales o temáticas de los textos, a fin de llegar a una especie de "confluencia" o mutua utilidad. Por ejemplo, es cierto que el cuento de hadas se acomoda a la perfección a los primeros años infantiles, pero también lo es que subyace una disposición innata del ser humano a la fabulación, y que lo que el cuento maravilloso potencia es la activación de un patrón simple y eficaz a estas edades; o, dicho de otro modo, que no son tan esquemáticas las correspondencias entre edades y (sub) géneros textuales, en todo caso, habría más bien una especie de "continuum", como lo hay también en la evolución de las llamadas fantasías infantiles (Gloria García 2007). 
Lo que sí está claro es que cuando hablamos de "adecuar" el texto hablamos de mediaciones y de mediadores (Cerrillo 2002), por eso no puede extrañar que un origen de estas lecturas sea el litúrgico, esto es, la ordenación de las lecturas según el calendario litúrgico, las celebraciones de los santos u otros motivos pastorales (Bettelheim 2006). El sacerdote elige un texto porque ponga de relieve algún aspecto peculiar que vaya a glosarse en la homilía. De hecho, hay un conjunto de lecturas asignadas para cada día en el leccionario ferial, de modo que se disponga de varios textos para una misma lectura, que el celebrante escoge conforme a lo que crea más adecuado a los oyentes. Todo ello conforma un macroconjunto textual, donde se arraciman salmos, profecías, textos de los Evangelios, cartas de San Pablo, etc. Es decir, un auténtico canon sagrado, que es el marca lo que es apropiado y, a su vez, perfila lo que debe decirse y, por ausencia, lo que debe excluirse, es decir, lo que no es revelación, o lo que la Iglesia considera como tal.

He aquí, por tanto, cómo dos mecanismos esenciales, el concepto de lectura apropiada, y el de inclusión/exclusión, cobran fuerza desde la propia tradición cristiana, y trasciende, pues, a lo literario tomado como simple disfrute o goce estético sin más pretensiones. Al contrario, la dimensión ética y social guía estos dos mecanismos, se selecciona y se excluye conforme a unos parámetros, y se inculcan el resultado de estas decisiones como si fueran lo natural.

Lo que queda fuera son lo que se han llamado las escrituras silenciadas, los géneros marginales o los sistemas culturales periféricos (Even-Zohar 2004), si bien hay siempre una fricción entre el "centro" y la "periferia" de estos sistemas culturales. Sin ir más lejos, las devociones populares (v.gr. las leyendas piadosas), son reabsorbidas con frecuencia y se integran en este corpus textual, gracias a los mismos mecanismos que ya utilizara Perrault al añadir a los etnotextos o versiones antiguas ciertos "retoques" de diversa índole, como agregar una moraleja en verso. Es la "purga que ha convertido en "apropiables" ciertos textos más o menos escandalosos por sus escenas u otras causas.

\section{LA FICCIÓN MANÍA, UNA PRÁCTICA DE APROPIACIÓN DE TEXTOS}

En este contexto, el escenario digital y en general la cibercultura está suponiendo un "vuelco" total, por los motivos que ya se han expuesto por especialistas de la talla de Eco, Landow, Piscitelli, etc. Nos vamos a centrar en un fenómeno emergente: el fan fiction. El estudio del fan fiction, que nosotros preferimos denominar, "ficción-manía" ha sido el objeto de la Tesis Doctoral Las Sagas Fantásticas Modernas y la Ficción-Manía: Lenguajes Literarios, Plásticos, Multimediales y sus Repercusiones Didácticas, que defendimos en la Universidad de Extremadura (Martos García 20o9). 
De antemano, lo más llamativo de este fenómeno es que la reescritura o "apropiación" de textos por partes de los fans no viene desde "arriba", ni por criterios socializadores ni por inducción del sistema educativo o académico-literario. Al contrario, es un fenómeno generado al margen de todos estos elementos, muy propio de la cultura de los adolescentes, esto es, orientada a una socialización horizontal y una alfabetización digital creciente, en choque a menudo con la "cultura letrada” o académica. Sí hay mediador, pero ése no es ya el profesor, bibliotecario o padre, con sus criterios de autoridad, sino el propio grupo, la red social, o, como se dice en los portales de fanfics, el "beta-reader".

Baste decir, pues, que las prácticas de fan fiction, igual que los blogs o los juegos, son síntoma de esta nueva cultura participativa y de convergencia (Jenkins), pero que, en esta caso, parten de esta nueva actitud del lector (pos)moderno de "revisitar" los textos que le sirven de referente (y que el mercado cuantifica como éxitos o best-sellers) para efectuar en él no sólo operaciones de (re)interpretación sino, en su caso, de apropiación creativa, dando lugar a reescritura variadas y en distintos lenguajes. Por ejemplo, no sólo debemos prestar atención a los relatos que se "cuelgan" en fanfiction.net u otros portales por parte de estos fans, también hay otros géneros y lenguajes que en el fondo evidencian el mismo fenómeno. Así, los post o comentarios de fans acerca de un texto de éxito o que congrega un interés especial, son vertidos en multitud de herramientas, desde foros a otros muchos soportes.

Cierto que esta nueva forma de "revisitar" estas obras, muchas de ellas ya clásicas, se hace desde unas "miradas" muy singulares, a menudo muy posmodernas, y en eso se parece a la apropiación que el urbanismo moderno trata de aplicar a los "centros históricos": la secuencia temporal o de estilos no es, por ejemplo, lo que más preocupa, sino, al contrario, se fomenta la yuxtaposición o la fragmentación, que vienen a ser señas de esta hipermodernización. Lo mismo pasa, en lo literario traslado a la ficción-manía, con muchas series novelescas o de origen mitológico, convertidas en objeto de culto como fanfics. Por no citar títulos de obras concretas como las de Tolkien o Lewis, piénsese simplemente en todos los ciclos mitológicos en torno a Hércules (y su spin-off Xena), vampiros, etc.

En todo caso, una práctica nueva de lectura/escritura, sensible a algunos de los aspectos positivos y negativos que venimos comentando. Por ejemplo, se desarrolla en un marco de lenguaje total y de "inter-medios" (Jenkins ), que hace que el fan conozca la referencia de su universo en varios lenguajes y además implica la reelaboración activa por parte de éste de elementos del universo preferido; sin embargo, en la parte negativa, el fan fiction también es proclive a crear monomanías y prácticas compulsivas al margen de todo pensamiento crítico, y, sólo bajo este aspecto, se podría entender como una práctica "parasitaria”, tal como valoró Cervantes a su imitador Avellaneda. 
Lo cierto es que tal práctica -llena de contradicciones en su misma raíz, a caballo entre la sumisión y la transgresión- choca bastante con las preconcepciones de profesores, editores o escritores, pues es un fenómeno relativamente nuevo que ha cogido por sorpresa a algunos de estos ámbitos. Por ejemplo, en las Sagas los metatextos o libros explicativos funcionan de una manera bastante singular, a modo de libros de acompañamiento que el público demanda para entender el universo en creación, a modo de introducciones, sinopsis, guías, y cubre así la necesidad que tiene el lector de orientarse en el material tan extenso de una saga.

También podría hablarse de un architexto, es decir, de un denominador común, de un patrón, de hecho, se habla en los fanfics de la versión canónica de una saga, a fin de no admitir aquellas continuaciones que se salgan en exceso de las convenciones asumidas por todos. También un filme como "Piratas del Caribe" usa el architexto, porque contiene las convenciones más importantes de los relatos de piratas. Del mismo modo, cuando James Barrie introduce en Peter Pan a los indios, no se refiere a un relato concreto, sino al género en su conjunto. Las sagas establecen relaciones con un architexto especial, los mitos de lucha, de estas historias arquetípicas toman los ingredientes básicos, y no tanto de tal o cual mito en particular.

Daniel Chandler (2002), por su parte, sustituyó el término hipertextualidad definido por Genette, por el de hipotextualidad con el fin de dotarle del significado actual. Aunque la relación aparente parece clara entre Hipertexto e Hipotexto, para destacar que éste es un texto subyacente de aquél, en la práctica Hipertexto se asocia ya a un texto electrónico o informatizado. En este sentido, entendemos por Hipertexto no sólo un texto que contiene a otro sino un texto o "nodo" informativo que puede llevar al lector/ receptor directamente a otros textos/nodos en la Red, sin importar su localización. En suma, el hipertexto se basa de nodos y enlaces, o tópicos y conexiones, pero en este uso ya aceptado, se diferencia bastante del uso que hace Genette.

El hipotexto, en cambio, es un texto subyacente con el cual el texto guarda una relación de dependencia, en cierto modo, de subordinación. Por ejemplo, la novela de caballerías es un hipotexto activo en el Quijote. El problema de los "hipotextos" es, en efecto, el de su visibilidad, pues depende de muchos factores, así el receptor infantil puede no conocer el hipotexto mitológico o folklórico que articula una historia como Shrek, o bien puede que tal vez lo conozca sólo parcialmente, por ejemplo a través de versiones cinematográficas como las de Disney (Díaz Armas, 2003). El resultado puede ser que ignore la estructura paródica que pueda tener un texto, en relación precisamente a su hipotexto: leer Caperucita en Manhattan o innovar sobre el cuento requiere, claro, conocer la "versión canónica". 
La relación del texto con otros textos, con el soporte material o con su entorno no acaba en estas categorías de Genette. Recientemente, se han sugerido otros elementos no menos distintos, como los que se denominan como "peritexto" o "epitexto", es decir, lo que rodea a un texto, lo que está en torno a un texto. Así, en las sagas los displays, carátulas de películas, campañas de promoción, iconos de todas clases... son elementos mediadores que ayudan a fijar el significado de la serie. De hecho, las imágenes de la película "El Señor de los Anillos" han tenido tal impacto que han fijado la forma en que los lectores perciben a Gandalf, Aragorn, Frodo...

En cierto modo, al fan fiction se le puede considerar un nuevo género, (igual que lo fue la sátira en la literatura latina²)aunque sea ahora un género marginal y a caballo entre el libro, Internet, las películas o los comics, y no asimilado por el "canon” de obras y temas que los ámbitos académicos y culturales establecen. Sin embargo, es algo que viene ocurriendo en la evolución literaria, géneros marginalizados en el s. XIX, como el terror o lo policiaco, hoy son plenamente admitidos.

Por todo eso, los textos de fan fiction son hoy en realidad "antitextos"3, textos que rompen y desafían las reglas de los que sí son admitidos por el "canon”; es una poética singular donde la pasión por escribir y el afán de compartir con el grupo el universo imaginario de que se trate, es más importante que todo, y eso repercute en una escritura nueva, que reescribe esos mundos ficcionales en claves nuevas.

Así que no es sólo una práctica de recepción sin más, no es como una lectura escolar, por ejemplo. Tiene más que ver con la cultura de la convergencia y de la participación de que habla Jenkins, donde la apropiación y la interpretación cultural adquieren la misma entidad que la producción. Debemos, a este propósito, una primera reflexión al profesor francés Bernard Lahire ${ }^{4}$ sobre los modos de apropiación de los textos en las lecturas populares, y que venía a poner en cuestión algunos tópicos o preconcepciones.

Por ejemplo, B. Lahire subraya que la lectura es una práctica más anclada en los medios populares de lo que se piensa, eso sí, orientadas y re-descubiertas desde una practicidad:

Pero, ¿qué muestran todas las encuestas, es que, lejos de reducirse a la lectura pobres

(menos frecuentes, menos complejas, menos hábiles, menos virtuosas ...), las lectu-

\footnotetext{
${ }^{2}$ Véase la Tesis doctoral de A. Luisa Coviella,"Sátira romana: género de fronteras y antitexto en Horacio y Persio", http://www.tesisenxarxa.net/TDX-o920IO6-I4I434/index.html

3 Concepto introducido por el semiólogo I. Lotman para representrar los contratextos que se oponen a un corpus canónico, o que son intencionadamente marginales respecto al "centro" del canon prestigiado social y académicamente. Es de destacar que muchos de los autores de fan fiction no se ven a sí mismos ni como imitadores ni como plagiarios, sino continuadores de un universo de fabulación que es objeto de veneración para ellos.

4 Lahire, B. (I993). “Lectures populaires : les modes populaires d'appropriation des texts”, Revue française de pédagogie, n ${ }^{\circ}$ (O4, I993, p. I7-26.
} 
ras ponen en funcionamiento modos de apropiación específicos de impresos, revistas, otros libros) que se caracterizan por un deseo de anclar el texto en otra realidad distinta a la única realidad en el texto: en una práctica de instalación en un área conocida, vivida, en los marcos, esquemas de experiencias pasadas y presentes...

La diferencia entre este lector popular y el lector letrado no está, pues, sólo en el número de libros o en las destrezas que uno y otro pone en juego, sino justamente en el modo de apropiación del texto. Las etiquetas como "popular" pasan a menudo por alto que lo que se produce realmente es el encuentro de obras o géneros singulares generados dentro de formas sociales específicas, con receptores que les aplican formas de apropiación específicas, propias tal vez de contextos distintos y distantes de las que generaron dichos textos. En pocas palabras, los modos populares de lectura no consagran las prácticas escolares o el canon académico, sino que a menudo son pragmáticos, utilitaristas. Llega incluso a enunciar este principio para contrastar el peso de la experiencia literaria y el de la no-literaria en el tipo de lector:

La lectura se aleja tanto más de la experiencia cotidiana cuanto el lector posee la competencia para anular estéticamente su lectura... Portanto, debemos preguntarnos cuál es el peso relativo de cada lector (cada clase de lectores), en cuanto a la experiencia ordinaria (éticas y prácticas) y la experiencia estética previamente adquiridas en el proceso de la lectura de un texto.

Dicho de otro modo, es algo similar a lo que ocurre en el campo del fan fiction. El fan no imita por un móvil literario más o menos abstracto, sino que la práctica y el artefacto resultante (el fan fic) se convierte en parte de un discurso de identidad y de integración con otros jóvenes con quienes comparte esta actividad.

Es curioso que, en el caso de los fanfics, el anclaje en otra realidad que no sea la literaria pasa por un proceso dialéctico, la tesis sería el emundo o referente conocido, la antítesis el mundo literario objeto de imitación, y la síntesis -negación de la negación, superación- el universo de ficción recreado que se quiere habitar, el paracosmos completado, que supone, claro, una reconciliación de los contrarios ("invento otros mundos para comprender éste"). Por eso el concepto de intertexto no es en estos casos tan irradiante como se supone, porque:

El anclaje de la lectura en una realidad distinta que la sola realidad literaria explica por qué el tema literario, el tema y los efectos reales producidos por el estilo o por el contexto (sabemos, por la televisión, el que escribe la novela o autobiografía) son a menudo puestos por delante del autor, el estilo, y que nunca se menciona cuando se trata de las novelas, los movimientos literarios o los editores.

Dicho de otro modo, esta forma de apropiación popular no se sustenta en el conocimiento amplio de otras referencias literarias, no puede anclarse en una cultura literaria 
(autor, estilo, etc.) sino en esta otra clase de indicadores. Por eso la elección de estos libros "en el modo popular" no se hace al azar sino que se fundamenta estrechamente en el tema, es decir, se vincular una disposición “ético-práctica”.

Por otro lado, la ficción se concibe como un equipamiento cognitivo, una suerte de “entrenamiento" (lo que Benjamin llama la dimensión práctica de la narración), y muy especialmente, como un espejo, un artefacto, una máquina de (auto)identificación. Muy unida, además, a todo lo que entendemos como alfabetización emocional, tal como expresa en sus conclusiones B. Lahire:

\begin{abstract}
A las disposiciones teóricas, estéticas o políticas se oponen las disposiciones éticas y pragmáticas de los hombres y mujeres de los medios populares, que, cuando se trata de literatura, implican un gusto profundo por la participación y la identificación: se quiere vivir la vida de los personajes, identificarse con el héroe o detestarlo, pero en cualquier caso, se tiene una reacción con los personajes escritos del mismo tipo que con los personajes de la vida real. Esta estética popular, este modo popular de apropiación de los impresos que es inseparable de la ética, no significa que estos adultos no sean capaces de "hacer callar la teoría", de "analizar" o de tener en cuenta el estilo de las obras, sino que requieren una relación más directa, una referencia más inmediata a la configuración de las prácticas o a patrones específicos de la experiencia. La constatación, por el conjunto de los profesores, de la diversidad de gustos y de investimentos específicos en materia de lectura en contextos sociales con bajo nivel educativo, puede constituir un paso hacia una mejor articulación de estos gustos y de las predisposiciones y de los dispositivos educativos.
\end{abstract}

En efecto, una de las características de los modos populares de apropiación de los textos es anclarlos en realidades prácticas. Se lee menos, sí, pero de una manera totalmente distinta a la lectura convencional o académica, primando los libros prácticos para hombres o mujeres, como recetas de cocina, libros de instrucciones para tejer o manualidad de todo tipo. Son textos ligados a gestos, acciones, instrucciones de uso, que tienen poca presencia en el corpus de textos académicos, y, sin embargo, forman parte del conjunto de textos más comunes en la vida cotidiana.

En estas categorías habría que incluir también, en el plano emocional, los libros de autoayuda, que son como los diarios antiguos, una forma de indagación en el saber vivir. Más que el tema, el estilo, la corriente o el autor, lo que prima en estos textos es la capacidad que puedan tener para que el chico se identifique con ellos, a menudo en compañía de otros, como la lectura de los antiguos tebeos. Por tanto, son textos que forman parte de un proceso de socialización horizontal. En este sentido las lecturas de los clásicos o de los vanguardistas, presentadas sin más, son in-apropiadas, son difíciles de ser incorporadas a esta practicidad, por su lejanía de códigos, su oscuridad o su densidad, factores todos de "ruido" o perturbación del mensaje. 


\section{Heterogeneidad}

Así pues, los individuos desde muy temprano se ven confrontados a contextos de socialización muy diferentes Eso lo vemos todos los días: las series de TV sobre Hércules y otros mitos, ¿no son acaso variaciones sobre un mismo universo narrativo?, y sin embargo nadie se escandaliza de que las "firme" alguien como autor. La diferencia suele estar en que el autor de fanfic no se plantea nada de esto, no pretende ganar dinero. Además, la llamada cultura posmoderna es también eso, hibridación y reciclaje de una tradición.

La calidad de estos textos es tan variable como la que se puede apreciar en un concurso de novelas; algunos son sobresalientes, otros mediocres, y algunos muy malos. El paso de estos textos de Internet al papel ya se está dando, al menos en España, conozco algunos casos, y a veces, las propias editoriales rastrean nuevos talentos entre estos escritores de fanfics. Ocurre lo mismo que con los blogs: hay numerosos blogs que han saltado a la letra impresa en forma de ensayos, diarios, etc. Lo cual demuestra dos cosas: la convergencia de los viejos y los nuevos medios, mucho más relacionados de lo que se piensa, y que la cultura digital no va contra la cultura escrita, en el sentido clásico de que habla Chartier, sino que, como en estos casos, la potencia o actualiza. En cuanto a relatos fanfiction de calidad, son tantos y de temas tan variados que exponer uno solo aquí sería una elección, además de ardua, injusta para todos los demás. Los parámetros de calidad del género del fanfiction son más abiertos que los de la literatura convencional, ya que no tienen que superponerse a un concepto de comercialización. En este caso estamos hablando de la literatura por amor a la literatura, y por amor a la obra a la que se rinde homenaje.

Por tanto, priman criterios estéticos y sensoriales (que se sepa “enganchar” al público), además de una adecuación al universo ficticio y/o a los personajes que se pretende reflejar. Los propios fans hablan del fanfiction, analizándolo como género, en blogs, páginas personales, foros... crean mecanismos para interactuar y ayudarse entre sí, y también para comentar y criticar sus obras en el más puro estilo de crítico literario. Existen, por tanto, foros donde se señalan los errores de fanfics que consideran de poca calidad; y también foros donde los lectores pueden votar por los fanfics que consideran mejores. La cultura del papel es el entorno tradicional de las editoriales y las librerías, pero poco a poco se irá viendo que la red y sus nuevas prácticas y escenarios de lectura y escritura también pueden ayudar a difundir y a vender, son nuevas relaciones que hay que explorar.

Sea como sea, no debe pensarse que los jóvenes sean siempre sumisos al mercado, de hecho el fan fiction surgió desde Star Trek precisamente porque el mercado no les daba todo aquello que necesitaban. La apariencia es que son dóciles a los lanzamientos del mercado, pero la realidad es que estas prácticas culturas emergen, porque hay una ruptura generacional evidente, los jóvenes hoy pasan más tiempo ante el ordenador que 
ante la TV o ante un libro, pero ellos han reinventado su uso, como se ve con las herramientas de la web 2.o.

Que la cultura impresa ocupa una parte pequeña de esta "dieta” no es el problema, no es un problema de cantidad o número de libros que leen; el problema es que el estudiante domine todos estos nuevos alfabetismos para ser un lector competente e informado, que forme criterio propio de adónde navegar y por qué. La escuela no puede anclarse en el pasado, tiene que ayudarles a formar estos mapas mentales, a ayudarle con estos itinerarios que ya no son sólo de un libro a otro libro, sino de un lenguaje a otro, o de un soporte a otro. Por ejemplo, el educador puede ayudar a visibilizar estas prácticas, porque, como dicen Barton y Hamilton, en la cultura escrita actual hay prácticas más dominantes, visibles e influyentes que otras, pero sólo por cuestiones de poder y economía. Lo bueno del fanfiction es el entusiasmo, la entrega desinteresada, la socialización horizontal, y todo ello son factores positivos y de resistencia frente a una cultura bastante deshumanizada. Como dice el filósofo P. Sloterdijk, ya no quedan más que utopías individuales, así que los cientos de mundos imaginarios con que se identifican estos "locos de la escritura" son otras tantas vías para conseguir, como dice R. Aparicio, inventar otros mundos a fin de comprender el nuestro.

En todo caso, de este fenómeno se hacen interpretaciones muy sesgadas. Una de ellas es la de identificador el aficionado al fan fiction con un perfil de joven "frik $\imath^{\text {", }}$, con todas las connotaciones negativas de la adolescencia, inestabilidad, confusión, sentimentalismo, inmadurez... Se generaliza, asimismo, dando el predominio del mundo de la escritura en fan fiction al sexo femenino y a una edad juvenil, por lo que el perfil tipo (aunque no exclusivo), podría corresponder a una chica adolescente, soñadora... Sin embargo, los únicos datos ciertos que sabemos nos los dan los portales dedicados a éstos, como fanfiction.net, con sus números de visitas y otros datos, y los hábitos parecen coincidir con los de los jóvenes internautas.

Ahora bien, hay que tener en cuenta que la identidad virtual no es precisamente un dato fiable, como es sabido, se puede crear y se crean avatares, de modo que tras el nick de una aparente jovencita romántica, puede hallarse en realidad un hombre maduro y su "alter ego". Además, los chicos no suelen confesar que escriben este tipo de cosas por razones que todos conocemos, empezando porque la libre expresión de los sentimientos es algo mucho más reprimido en el estereotipo del varón.

También hay diferencias según los subgéneros del fan fiction, que son muy distintos, al igual que ocurre con la literatura convencional. Ciertas obras ficticias que sirven de fuente de inspiración (denominadas fandoms por los aficionados a este arte), atraen a más chicas o más chicos dependiendo de su materia. Así, por ejemplo, en los fanfics basados en videojuegos hay una proporción mayor de chicos escritores que, por ejemplo, en los 
fanfics basados en novelas, series de TV... La temática del fanfic en sí también influye. Los chicos se inclinan por escribir fanfics de acción, y las chicas suelen tratar géneros como el romántico o el dramático, aunque no siempre. El sesgo de edad se manifiesta más ya en la complejidad del relato que en el tema en sí, ya que hay subgéneros, como el romántico, que son preferidos por todas las edades.

De todas formas, y como siempre se dice, no es conveniente ni correcto generalizar. Volviendo a la idea del fan fiction como un género más, podemos decir que, cada escritor y cada lector constituyen un mundo. Podemos encontrar muy fácilmente escritores de poca edad con un dominio del discurso narrativo superior al de gente más madura, chicas que prefieran el terror y chicos que prefieran el romance (por poner un ejemplo); personas ya maduras, casadas y con hijos, que encuentren en el fan fiction una manera de expresarse, etc. En pocas palabras: "hay de todo".

Lo único cierto, por tanto, es que los autores de fan fiction se comportan de forma altruista, exponen sus creaciones sin ninguna limitación, se dejan aconsejar por sus "iguales" y conforman redes que se ayudan entre sí; se mueven, pues, por factores emocionales o profesionales, más que por afán de conocimiento, status profesional o deseo de ganar dinero. Ni siquiera la palabra literatura y sus terminologías profesionales aparecen con frecuencia, los que escriben fanfics no se preocupan del academicismo literario, pese a que su conducta se parece mucho, a veces, a la del escritor novel y ya hemos visto que, en algunas ocasiones, se ha producido el salto del fanfic al libro impreso.

En resumidas cuentas, no hay un perfil único, y prueba de ello son los últimos enfoques, bastante curiosos, con que se ha abordado el fenómeno a fin de trazar un perfil psicológico de estas personas. Los psicólogos infantiles ya detectaron, entre las fantasías infantiles, aquellos niños que, además del amigo invisible y otros juegos, llegaban a imaginar mundos completos, con su geografía, personajes, nombres... y los pintaban y escribían durante años. A estas fantasías persistentes las llamó "paracosmos", y como ha hecho la profesora Gloria García Rivera, es fácil cotejar los rasgos de estos niños con los de grandes talentos literarios, como Tolkien y otros mundos, para ver que los mecanismos son bastante parecidos. Lo que nos interesa es que tanto estos niños como los adultos se comunican compartiendo un universo completo de ficción, que es un universo alternativo al nuestro, levantado por la magia fabuladora de la imaginación.

Luego, los terapeutas han hablado de técnicas como las del soñar despierto, que vienen a coincidir con este perfil que supone del fan que todo el día está jugando el papel de su héroe o saga favorito. E incluso, en la literatura médica, se habla de hiperlexia y de hipergrafia como perturbaciones de la lectura y la escritura, como ese lector compulsivo que imaginamos en la figura de D. Quijote, o ese escribiente también compulsivo, que se pone durante horas en su blog o en su fanfic. Se ha conjeturado desde la neurología, pues, 
que el escritor de fan fiction sería como ese tipo de escritor creativo abierto, impulsivo, ansioso, con una alta afectividad, emocionalmente inestable, poco socializado, inconformista, con trastornos de bipolaridad incluso. Suelen proceder de entornos que no valoran las capacidades artísticas, y eso da más invisibilidad precisamente a esta práctica, e incluso se relacionan con perfiles de orfandad y/o de madres con las que no se relacionan emotivamente, y, en cambio, muestran desempeños altos en la escuela, con indicadores de pensamiento divergente o creatividad.

Ciertamente, estos perfiles individuales no valen del todo, porque las prácticas de lectura y escritura hay que entenderlas en contexto, es decir, es fundamental el componente social, de modo que es fundamental el estímulo que ellos puedan tener en los diferentes escenarios sociales en que se desenvuelvan. Hoy, por ejemplo, la llamada cultura friki es un exponente de que comportamiento antes juzgados anómalos, se pueden exhibir sin la reprobación social. Un joven puede hablar de sus aficiones o gustos dejando al lado ciertos prejuicios y estereotipos sociales. De hecho, el fan fiction permanece marginal no sólo porque apenas haya estudios o consideración académica del fenómeno, sino porque ni siquiera se valora como parte de una cultura digna de ser fomentada.

Por eso el fan fiction aparece como un fenómeno importado y subcultural, asociado sólo a productos de aparente bajo nivel cultural, como las series, telenovelas, etc. La realidad es que la práctica del fan fiction está en la propia historia literaria y en la tradición más antigua: no sólo se cita el caso de Avellaneda respecto al Quijote, se dice también que la propia Eneida es una reescritura y una continuación intencionada de los "éxitos" de Homero.

Particularmente, hemos reivindicado el valor educativo de este fenómeno en la citada Tesis Doctoral, y he propuesto incluso su denominación que creo más correcta, "Ficción-manía", pues no se olvide que "fan" no es una palabra inglesa sino castellana de raíz latina, "Fan" viene de "fanaticus" (el que cuidaba un lugar sagrado"), y tiene un origen religioso (de "fanum", templo, de donde viene "profano"), a fin de resaltar dos hechos: que no es una palabra de origen inglesa sino latina y que tiene un origen ancestral religioso , y, por tanto, no es una simple moda que pueda "achacarse" a adolescentes entusiasmadas con un cantante, y ni siquiera a sus primeros cultivadores, en concreto, los seguidores de la saga "Star Trek".

\footnotetext{
5 En realidad la palabra griega * phantasía* y fan ‘aparición’ e ‘imaginación’ parten de la misma raíz es el importantísimo verbo griego (phaíno) 'aparecer, mostrar(se), manifestar(se)', brillar, origen de numerosas voces en griego y en castellano como fenómeno, fantasma, fantasía, fanum. Fanum equivale a santuario, lugar de revelación, de iluminación (no es propiamente el edificio, eso es templum, sino todo el lugar), por eso tiene que ver con la luz (fanal: farol) y de ahi fanaticus, el cuidador de ese lugar sagrado, que se mostraba particularmente exaltado e inspirado. Y de fanaticus la contracción es fan, que empieza a usarse con este mismo sentido desde los admiradores de Presley los Beatles.
} 


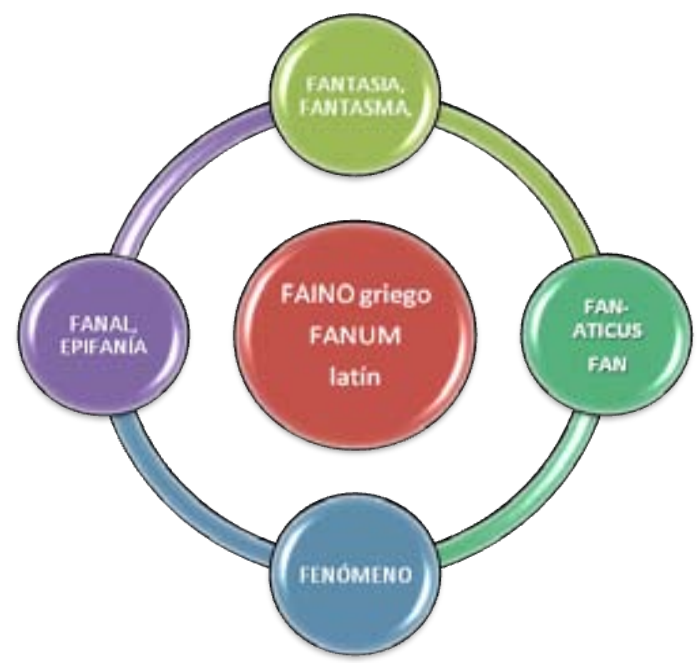

Por tanto, el estudio de la ficción-manía no debe reducirse a un estudio sociológico de comportamientos extravagantes sino que en realidad se refiere a las nuevas prácticas de lectura, tanto en continentes como en contenidos. De eso no podemos extendernos ahora, pero no puede perderse de vista que la ficción-manía está ligada a un género igualmente nuevo -y viejo a la vez, si buceamos en la épica- que son las sagas.

Tampoco podemos perder de vista su nuevo modo de practicar lo que se ha llamado la "interartisticidad", porque el autor de fanfics está vinculado a prácticas como el cossplay, el fan art, las fan movies, los audio-podcast, es decir, está familiarizado con los entornos multimedia que favorecen la interactividad y la expresión no lineal. En suma, son nuevos lectores y escritores que se adentran en los nuevos alfabetismos, sin que ello suponga renunciar a la herencia de la cultura escrita clásica, al contrario, vemos continuos "guiños" y reflujos entre una obra (por ejemplo, "El viaje de Chihiro", un anime de 20OI) y sus referentes clásicos, mitológicos y literarios. De modo que entender todo este mundo no implica, como a veces se cree superficialmente, devaluar la cultura sino situarla en los nuevos e inevitables escenarios del s.XXI.

\section{APROPIARSE O COMPARTIR LOS UNIVERSOS DE FICCIÓN}

Así pues, debemos poner un poco entre paréntesis tópicos, como el que esta clase de fenómenos va en contra de la cultura escrita, cuando es al revés, y tampoco debemos fiarnos de ideas preconcebidas, como que estos chicos sólo son personajes frikis o adolescentes compulsivos. Lo primero, es conocer de cerca qué pasa en estas nuevas pizarras digitales que son los ordenadores, y qué es toda esta literatura sin nombre surgida al amparo de la cibercultura. 
Conocer estos textos y sus creadores tal vez no nos sirva del todo para explicar del todo el talento de los escritores del pasado, pero sin duda sí nos ayudará a descubrir cómo fomentar los talentos de los escritores del futuro, que son los que vivirán en los nuevos escenarios culturales y los que de verdad pueden resistirse, desde su propia creatividad, ironía u otras forma de tratamiento, a todo lo que el mercado trata de imponer. La escuela tiene que entender que el blog, el fanfic o el videojuego son síntomas de esta nueva cultura de la participación (Jenkins), y que puede y debe utilizarlos en provecho de la promoción de las personas y de su libertad.

El panorama descrito nos arroja interrogantes muy interesantes. Uno de ellos es el concepto de autor y, unido a él, el de propiedad intelectual. Ciertamente, de lo que se apropia el fan no es de la literalidad del texto de Rowling, lo cual sería plagio sin más, sino de un "universo compartido", concepto propio de las fantasías infantiles (paracosmos).

En todo caso, queda claro que "todo texto es un intertexto" y que un autor no puede, y menos en el actual contexto, defender su obra como un patrimonio exclusivo y excluyente; al contrario, los editores y creadores actuales de sagas alientan cada vez más el movimiento de fans, y no sólo por motivos comerciales. Se crea un hilo directo que en la lectura no digital rara vez existía, y el escritor puede ver así cómo su ficción toma derroteros insospechados, o en todo caso, puede hacer el "feed-back" oportuno.

\section{LECTURAS PARA LA APROPIACIÓN Y PARA LA INCLUSIÓN: LA ALFABE- TIZACIÓN COMO PRÁCTICAS Y ESCENARIOS MÚLTIPLES.}

En el fondo, todo lo que estamos discutiendo nos aporta una visión de la lectura desde la sociedad, no desde el individuo aislado porque Internet, pese a su aparente fragmentación y aislamiento, se apoya en un concepto de inteligencia colectiva y de trabajo colaborativo, como bien se evidencia desde las herramientas de la Web 2.o Hablar de la sociedad es hoy hablar de la diversidad, y, en el mismo sentido, hablar de alfabetización no es hablar hoy de enseñar a leer y escribir sino de prácticas y escenarios múltiples. Según Elsie Rocwell ${ }^{6}$ :

Estas discusiones abren un campo para abordar las múltiples historias de apropiación de la escritura. Quisiera reparar un momento en la idea de apropiación, utilizada por Roger Chartier en conexión a la lectura, ya que permite -más que otros conceptos, como difusión, socialización, o adquisición- insistir en dos cuestiones. Primero, acentúa el rol activo de los sujetos involucrados en tomar para sí y hacer uso de la escritura. En segundo lugar, permite examinar los cambios que pueden sufrir los bienes culturales, como la escritura, cuando son apropiados por los sujetos. En palabras de Chartier, «.... la

\footnotetext{
${ }^{6}$ Rockwell, E. 200o. « La otra diversidad: historias múltiples de apropiación de la escritura. ». DiversCité Langues. En ligne. Versión disponible en http://www.teluq.uquebec.ca/diverscite. Subrayados nuestros.
} 
apropiación siempre transforma, reformula y excede lo que recibe... » (Chartier I99I:I9, mi traducción). Estos cambios se marcan en los productos de las diversas prácticas culturales que involucran a la lengua escrita.

Así pues, no hay duda de que este rol activo de los sujeto o los cambios que ellos infieren en los "bienes" que manejan, definen a la perfección la naturaleza del fan fiction. Apropiarse de la lectura literaria, para los cultivadores del fanfic, no es adoptar la actitud pasiva que antes veíamos respecto a los textos canónicos: al contrario, y en las acertadas palabras de R. Chartier, se los "transforma, reformula, excede..."

A ello hay que añadir que no sólo hablamos de las competencias básicos de lectura y escritura stricto sensu, sino de todas las otras alfabetizaciones añadidas (visual literacy, computer literacy, Graff I987). Chartier lo plantea muy bien cuando habla de la dicotomía entre lo que él llama la lectura salvaje, esto es, la lectura sin digerir de todo lo que la Red pone a disposición de un adolescente carente de educación literaria, y la herencia de la”cultura letrada”, enrocada en ámbitos académicos y/o eruditos.

Las llamadas tecnologías digitales interactivas, conforman el escenario final para lo popular, que ahora se puede entender como hipertextualización o virtualización de la ciudad letrada?. Lo popular se revela en la apropiación que jóvenes y otros sectores marginados de la ciudad letrada hacen de los nuevos repertorios tecnológicos para recreary poetizar su vida y para operar como productores directos y autónomos de obras (así sean obras menores) y para resistirse a las formas del control y dominación contemporáneas.

\section{PRÁCTICAS PARALELAS. FORMAS EMERGENTES DE LECTURA Y CREA- CIÓN LITERARIA EN LA RED}

Luther Blissett es el seudónimo colectivo de un movimiento, que empezó como un proyecto cuyo momento álgido transcurrió de I994 a I999, al amparo de ideas vanguardistas de artistas, activistas y performers de Europa y Norteamérica. Entre otras leyendas, se cuenta que muchos miembros de este colectivo se identificaron con el personaje de Paul Newman en "El castañazo”, Reggie Dunlop, capitán de un equipo de hockey en ruina que decide entregarse a la violencia para atraer público, con considerable éxito, y que pone de evidencia precisamente la espectacularidad y las audiencias como fenómenos de la posmodernidad. También se ha hablado de Umberto Eco como inspirados de algunos de los postulados de este movimiento.

${ }^{7}$ Cf.. op. cit,, J.A. Rodríguez Ruiz, Cultura digital: último escenario de lo popular 
Henry Jenkins lo explica de forma muy acertada, bajo el provocativo título de "Cómo "El castañazo" inspiró una revolución cultural Una entrevista con Wu Ming Foundation Traducida en castellano por Nadie Enparticular" ${ }^{\text {, }}$, desde donde se lanzan ideas de tanta fuerza como las siguientes:

... hemos lanzado diversos proyectos de escritura colectiva. El primero ha sido Ti chiamerò Russell [Te llamaré Russell], y la idea era bastante simple: hemos escrito el primer capítulo de una novela de ciencia-ficción, y cualquiera podía escribir y enviarnos los capítulos sucesivos. La selección de los capítulos tuvo lugar en público, en un blog temporáneo administrado por nosotros. Un jurado escogía las tres versiones más aptas para cada uno de los capítulos y la gente podía votar su versión favorita, que se convertía en el siguiente capítulo de la secuencia "oficial" (es decir, aprobada colectivamente). Pero las otras versiones quedaban disponibles como fuentes de inspiración, y así se fue creando una red de "bifurcaciones" de trama y "callejones sin salida". No hubo un último capítulo "oficial", todas las versiones fueron publicadas ex aequo. El resultado más importante de este experimento ha sido el nacimiento de otro colectivo de escritores, Kai Zen (en japonés significa "perfeccionamiento continuo"). A su vez, Kai Zen ha puesto en marcha otros proyectos similares, y su primera novela será publicada por la mayor editorial italiana en unas semanas.

Así pues, en estas prácticas paralelas, que bien podrían ser entendidas como antitextos o antidiscursos por lo que tienen de manifestaciones al margen de lo que el mercado, el canon o las instituciones académicas auspician, vemos un sincretismo de estos nuevos fenómenos: convergencia de nuevos y viejos lenguajes, y reflujos de éstos, pues, por ejemplo, cada vez son más los casos de blogs o relatos de fanfics que luego "saltan" a la letra impresa (son recuperados por la cultura académica, se podría decir también).

\section{CONCLUSIONES: CREACIÓN COLECTIVA Y CULTURA POPULAR}

El concepto de "creación colectiva” ha hecho "correr ríos de tinta”, a propósito de la épica y de otros temas literarios. No es nuestra intención abordar aquí ese asunto en todos sus ángulos, pero sí "iluminarlo" a la luz de lo que Internet o nuevos fenómenos, tales como el auge de las sagas fantásticas o la ficción-manía, están suponiendo. Así, lo que actualmente se denomina "escritura colaborativa" es en realidad un concepto que ha ido evolucionando de forma acompasada con las poéticas y las prácticas sociales de la lectura en cada momento histórico. Por citar un caso, en las novelas clásicas, teníamos continuaciones "autógrafas", es decir, cuando el autor retomaba una fábula, pero también y continuaciones alógrafas, como el segundo tomo de Avellaneda, juzgadas siempre entonces como algo malicioso y agresivo. Es decir, era una práctica unida al concepto de falsificación, a la intención de apropiarse de algo con fines ilícitos.

\footnotetext{
${ }^{8}$ Véase http://www.wumingfoundation.com/italiano/wumingylaculturapopular.pdf
} 
De hecho, dentro de la mitología romántica sobre el genio, parecería que sólo la genialidad de un autor podría asegurar la consistencia de un universo de ficción, que los lectores podrían compartir, pero sólo pasivamente.

\section{Las aportaciones básica de Genette y Landow}

La crítica textual y la propia praxis de la narrativa posmoderna va a desmentir en gran medida estas preconcepciones, y esto va a surgir a partir de frentes distintos, pero convergentes, que van a poner en cuestión y actualizar dichas concepciones. De todos modos, la crítica textual va a suponer una renovación conceptual profunda, quizás un hito esencial sean las categorías propuestas por Gennete para abordar el tema de la transtextualidad, en el marco de su conocida visión de la escritura como "palimpsesto"9.

En todo caso, a partir de este concepto de "transtextualidad" de Genette (I989), se ha focalizado el análisis de un texto no sólo como una unidad comunicativa dotada de sentido en sí misma, sino también como una unidad que se relaciona con otras unidades, pues está claro que los textos -sea cual sea la forma en que los acotemos- no se producen ni se leen tampoco de forma aislada, sino en interacción con otros textos: todo texto es, pues, un intertexto, un árbolen un bosque, donde sí se cumple aquello de que "los árboles no dejan ver el bosque".

Por otro lado, literatura en Internet, en el amplio sentido de la palabra, o bien la literatura electrónica, en el sentido más específico de literatura generada desde/para la red y el multimedia, son cuestiones que pueden y deben ser abordadas convenientemente, en un nuevo marco conceptual, que es el que describe Landow al examinar la convergencia o confluencia de la teoría crítica y de la tecnología precisamente en el concepto de "hipertexto". De hecho, algunos autores, como D. Casacuberta o Sergi Jordá, hablan de "creación colectiva", pero nosotros preferimos sustituir este concepto tan "escurridizo” por el de hipertextualidad alógrafa. Siguiendo la propia “poética” del hipertexto, un texto puede ser comentado o "revisitado" en múltiples claves, lenguajes y formatos, para parodiarlo, completarlo, modificar algo sustancial (los finales, por ejemplo), ilustrarlo (fan art), etc.

\footnotetext{
9 Los ejes de su reflexión son: A) La intertextualidad: « relación de copresencia entre dos o varios textos, esto es eidéticamente y las más de las veces, que se manifiesta por la presencia de un texto dentro de otro, »

B) La paratextualidad: « la relación que el texto mantiene, dentro del conjunto formado por una obra literaria, con su paratexto : título, subtítulos, intertítulos ; prefacios, postfacios, notas, prólogos y proemios, etc. "

C) La metatextualidad: « la relación llamada de comentario, que enlaza un texto con otro del cual está hablando, sin citarlo forzosamente. »

D) La arquitextualidad: « El conjunto de las categorías generales, o trascendentales, -tipos de discursos, modos de enunciación, géneros literarios, etc-, que determinan cada texto singular. »

E) La hipertextualidad:“" cualquier relación uniendo un texto B (hipertexto) con un texto anterior A (hipotexto), que se inserta en aquél de un modo que no sea del comentario. »
} 


\section{El concepto de escritura alógrafa según Anne Besson}

Las Sagas Fantásticas (Martos García, 2007) se prestan especialmente bien a estas relaciones que traza Genette, porque no olvidemos que son megaestructuras, es decir, conjuntos narrativos ("ensembles romanesques", en terminología de Besson) muy amplios, y, por tanto, casi unos "megatextos", en los que necesariamente se producen relaciones de todo tipo.

Las sagas, o el "ciclo", como prefiere llamarlas la profesora Anne Besson, es su campo de trabajo (véase Bibliografía), y no es casualidad que sea la ficción fantástica y, en particular, la que más se relaciona con la narración serial, donde más se evidencien estos principios.

De hecho, las TIC y el auge del género fantástico (por ejemplo, las sagas) están evidenciando prácticas de lectura y escrituras emergentes, donde "el texto continuo", la narración serial, la transficcionalidad (Richard Saint Gelais), los fanfics, los blogs y otra serie de fenómenos concurrentes están aflorando como síntomas de un nuevo paradigma donde el lector, la escritura libre o la nueva "imprenta" universal en que ha convertido Internet ponen en cuestión los conceptos clásicos de obra, autor o género.

Anne Besson actualiza, pues, lo que Genette llamaba la escritura alógrafa pone de relieve la importancia de la creación colectiva, tal como ocurre en Internet en los círculos de fan fiction, y ya desde luego el concepto de obra como texto acotado se pone en cuestión cuando hablamos de megaestructuras como las sagas fantásticas, cuyos "cierres" (Lázaro Carreter) se van creando según dinámicas nuevas, que además han atender la ramificación de estos relatos en distintos lenguajes y soportes (cine, televisión, manga, videojuegos...).

La ficción fantástica y las TIC parecen, pues, un escenario ideal de estas nuevas "transtextualidades", la propia composición de las sagas como una serie de libros o "entregas", con sus precuelas, secuelas y su tendencia a ser escrita por varios autores (que es la forma más simple de entender la escritura alógrafa), abre interrogantes sobre los conceptos clásicos de "obra" y "autor", y a ello está contribuyendo su implicación, como decimos, con prácticas alternativas como el fanfiction o los blogs. Sobre el fundamento de conceptos como "transficcionalidad" (R. Saint-Gelais) o "transmedialidad" (Jenkins) debemos indagar los nuevos modos de lectura apropiados para estas narraciones seriales, volcados más hacia una lectura multimedial y extensiva, más cercana desde luego a las prácticas de lectura hipertextual en Internet, que se ha comparado al "surfing", y a la poderosa influencia de la industria del entretenimiento y su producción, cada vez más programada, de "inter-medios". 
En conclusión, a raíz de estos conceptos de apropiación, creación colectiva, etc., es importante constatar la nueva visión de cultura popular que estos fenómenos están fomentando, a la luz de la reflexión de H. Jenkins ${ }^{\mathrm{ro}}$ :

La relación entre las dimensiones de la "popular culture", "cultura popular", "cultura folk" y "cultura de masas o masiva" hoy está en vías de redefinición, pero solamente podremos entenderlas si evitamos confundirlas entre sí. Hasta hace poco se llamaba "cultura de masas" a aquella que (producida y reproducida industrialmente) había reemplazado a la vieja cultura popular (en el sentido de "folk").

El embrollo aparece porque en inglés a la cultura de masas siempre se la llamó "popular culture" (para hacer hincapié en el hecho que no está dirigida solamente a elites reducidas, sino que apunta a su aprovechamiento por parte de un gran número de personas). Sin embargo el acento se desplaza: si el calificativo "de masas" define a la cultura desde el punto de vista de quien la produce, la distribuye y la promueve, el adjetivo "popular" la define desde el punto de vista de quien la aprovecha, la incorpora en su propia vida, se reapropia y la pone en discusión.

En resumen, "popular culture" es la cultura de masas entendida principalmente como fenómeno social, antropológico. Las transformaciones en curso están esfumando las distinciones entre quienes producen y quienes aprovechan. Ya era un límite "poroso"y repleto de agujeros, pero hoy la red está desmantelando todos los puestos de guardia. Por un lado el mainstream tiene menor importancia que antes (final de la "hit culture": los discos de éxito venden increiblemente menos que antes, las películas de éxito recaudan mucho menos en taquilla), por otro lado hay una vertiginosa y borboteante proliferación de nichos de consumo/rescritura/reapropiación.

Esto viene a reafirmar lo que el profesor J. Aguirre viene subrayando como un fenómeno esencial, la fragmentación de las audiencias, y cómo al lector/receptor masivo propio de medios masivos, como lo han venido siendo la televisión, la radio o el periódico (y el libro también, aunque de un modo sui generis), le está sustituyendo un lector/ receptor que se identifica con ciertos productos o "textos" (en el amplio sentido de la palabra) de una forma especialmente activas y participativa, es decir, que se acerca a lo que llamamos fan. Es decir, lo de cultura de masas importa menos que lo de "cultura popular", estratificada.

En este contexto, aparecen las narraciones transmediales y las dinámicas de creación colectiva en la era de la Red, formando discursos que se solapan y yuxtaponen, aunque por su parte las productoras traten de "encadenarlos", de presentarlos como parte un marketing. Sin embargo, la filosofía nueva del "procomún” busca justamente lo contrario, la "reapropiación pública de lo público" ", y de ahí la importancia de la creación colectiva.

\footnotetext{
IO Art. citado

II Véase http://www.archipielago-ed.com/77-78/index.html
} 
En cierto modo, éste es el fruto emergente de la nueva cultura popular: (todos trabajamos) juntos para contar al mundo una historia, crear una leyenda, dar vida a un nuevo tipo de héroe popular. En enero de 2ooo, nace un nuevo grupo, Wu Ming. Wu Ming elabora el manifiesto Omnia Sunt Communia sobre la cultura popular. Aquí entran las prácticas de la narración trans media, la dinámica de la creación colectiva, autoría múltiple, narrativa cross-media, creación de mundos. También usan los juegos de identidades, guerrilla-juego de rol, colisión entre viejos y nuevos medios, prácticas orientadas al copyleft, mofas mediáticas, avant-pop, Mash-up, etc, en la época de la red ${ }^{\mathrm{I2}}$.

Contexto, en el que, como vemos, encaja perfectamente la literatura Fanfiction escrita por fans de libros, películas, dibujos animados y series de televisión, que usan los personajes de un universo de ficción compartido y re-creado por varios (escritura alógrafa). El horizonte de debate que se abre es espectacular, y tiene repercusiones para nuestra concepción de la literatura, de la educación estética y literaria, de la sociedad misma que se está articulando en relación a sus nuevas - y paradójicas- "prácticas letradas", como diría R. Chartier:

Y aquí se presenta nuevamente el embrollo: según quienes se ocupan de esta nueva cultura "participativa" (fanfiction, mash-up, machinima, brick films, etc.) la "popular culture" actual tiene en sí misma muchas características típicas de la vieja cultura folk preindustrial, pero en un contexto nuevo, de ultramodernidad.

¿Somos capaces de entender estas cosas? ¿podemos discutirlas? ¿o preferimos acusar a quienes se ocupan de ello por "hablar demasiado" y por no ocuparse de la cultura sino más bien de basura? ¿En serio se puede pensar que podemos seguir diciendo hoy que "las masas" son rehenes del "consumo pasivo" reproponiendo sin alteraciones los análisis de hace cincuenta años? ¿En serio hay alguien que piensa "ocuparse de la cultura" rechazando todo esto, que es un terremoto cognitivo propiamente dicho?

En efecto, "ultramodernidad", "terremoto cognitivo" o "cultura participativa" son expresiones acertadas para describir lo que "se nos viene encima" y que, sin duda, es una expresión de todo el poder de la "con-fabulación”, es decir, de la creación colectiva. Lo cual concuerda con el planteamiento inicial de R. Chartier: las élites y las clases subalternas llegan a compartir textos y discursos, igual que Perrault y los narradores populares, aunque los mecanismos de apropiación se acomoden a las cosmovisiones de cada grupo. Lo interesante es que las mezclas, los entrelazamientos, la hibridación, en suma, permiten configuraciones especiales donde cada uno es capaz de expresarse, la Biblia clásica y las nuevas "biblias" modernas (las sagas, por ejemplo) son buena muestra de ello, al permitir estrategias de actualización y participación, esto es, de apropiación, sumamente flexibles. De ahí que hayamos elegido como emblema de la apropiación moderna el fe-

${ }^{\text {I2 }}$ Véase http://rle2005.blogspot.com/ 
nómeno del fan fiction, o ficción-manía, que se basa en una re-construcción del sentido de otros textos de referencia, y que sólo es entendible a la luz de las nuevas prácticas culturales.

Por otra parte, en las sagas y en la ficción-manía hemos constatado la importancia de los fenómenos emocionales: hay hiperlectores e hiperescritores que llegan incluso a ser compulsivos. El impulso inicial está en la motivación, y no tanto en el talento o la inteligencia. Luego intervienen otras necesidades, insospechadas para el individuo, que se canalizan por la escritura creativa, tales como necesidades emocionales (ser alabado, o identificarse con alguien), intelectuales (conocer) o sociales (ascender). De todo esto se deduce un patrón didáctico claro: se debe alentar una alfabetización integral, no sólo tecnológica, hacia las nuevas prácticas de lectura, que hagan posible la apropiación en los diferentes niveles, cultura letrada, cultura mediática y cibercultura. 


\section{BIBLIOGRAFÍA}

-Aguirre Romero, J.M. (2OOI). "Nuevas fronteras y escenarios culturales en la Sociedad de la Información”, Espéculo, n I8, Obtenido el 4 de Octubre de $20 I$ desde http://www.ucm. es/info/especulo/numeroi8/fron_cul.html

-(2OOZ). "Reinventar la actualidad: los Medios digitales y la transformación de las audiencias", Espéculo, no 37 .

- Barton, D. (1994). Literacy: An Introduction to the Ecology of Written Language. Oxford: Blackwell-

- Besson, A. (2004). D’Asimov à Tolkien, cycles et séries dans la littérature de genre, París: CNRS Editions «Littérature»

(2005) "À la croisée des mondes fictionnels: cycle, littérature de jeunesse et sémiotique des mondes possibles chez Philip Pullman". Cahiers Robinson. Arras, nº I7, pp. I25I44.

- Bettelheim, B. (2006). Psicoanálisis de los cuentos de hadas. Barcelona: Editorial Crítica

- Bowman, S, y Willis, C. (2003). We Media. How audiences are shaping the future of news and information. Obtenido el ı2 de Octubre de 20 II desde http://www.hypergene.net/wemedia/download/we_media.pdf

- Cavallo, G. y Chartier, R. (dirs.) (1998). Historia de la lectura en el mundo occidental. Madrid: Taurus

- Casacuberta, D. (2003): Creación colectiva: en Internet el creador es el público. Barcelona: Gedisa.

- Cerrillo y Garcia Padrino (I996). Hábitos lectores y animación a la lectura. Editorial Universidad Castilla - La Mancha.

- Cerrillo, P. (2002). Libros, Lectores y mediadores, Ed. Universidad de Castilla-La Mancha, - Chandler, D. (2004). "Intertextuality". In Semiotic for Beginers. Obtenido el I5 de Septiembre desde http://www.aber.ac.uk/media/Documents/S4B/semog.html

- Combettes, B. (I987). "Types de textes et faits de langue” en Practiques, num. 56, páx. $5^{-\mathrm{I} T}$.

- Díaz Armas, J. (2003): "Aspectos de la transtextualidad en la Literatura Infantil”, en Intertextos: aspectos sobre la recepción del discurso artístico / coord. por Antonio Mendoza Fillola, Pedro César Cerrillo Torremocha, pags. 6I-98, CEPLI - UCLM

- Ducrot, O. e Todorov, Tzvetan (I974). Diccionario enciclopédico de las ciencias del lenguaje. Madrid: Siglo XXI de España Editores.

- Fernández Villanueva (I99I). “Tipologies textuals” en COM, suplemento 8, páx. 26-3I

- Genette, G. (1982). Palimpsestes La littérature au second degré, París: Editions du Seuil, Points Essais.

- Graff, H. J. (199I). «Literacy, Libraries, Lives: New Cultural and Social Histories». Libraries \& Culture, 26.

- Idárraga Franco, H.F. (2009). "Sensorium e Internet. Una aproximación al fenómeno tecnológico desde la obra de Walter Benjamín”, Ponencia en VII Bienal Iberoamericana de la Comunicación, Blog de la VII Bienal Iberoamericana de la Comunicación en Chihuahua, México.

-Jenkins, H. (2006). Convergence Culture: Where Old and New Media Collide. New York: New York University Press. 
(20o6b). Fans, Bloggers, and Gamers: Exploring Participatory Culture. New York: New York University Press.

- Kraus, D. (I999). «Appropriation et pratiques de la lecture», Labyrinthe, 3 , Thèmes $\left(\mathrm{n}^{\circ} 3\right.$ ) - Landow, G. P. (1997). Hypertext 2.o. The convergence of contemporary critical theory and technology, John Hopkins University Press.

- MIT Press

(I993) y Delany, P.. The digital word. Text-based computing in the humanities, The

I998. (comp.) Teoría del Hipertexto, Barcelona: Paidós

- Marchese, A. e Forradellas, J.(I986). Diccionario de retórica, crítica y terminología literaria. Barcelona: Ed. Ariel.

- Martos García, A. E. (2007). "Ficción cartográfica y sagas (de los libros de acompañamiento a Google Maps)", Espéculo, no 37 , Obtenido el 24 de Octubre de 20 II desde http://www. ucm.es/info/especulo/numero37/cartogra.html.

. (2008). "El poder de la con-fabulación. Narración colectiva, fan fiction y cultura popular”, Espéculo, n 40, Obtenido el 2I de Octubre de $20 I$ desde en http://www.ucm. es/info/especulo/m_amo/amo-4.html dura (2009). Introducción al mundo de las sagas. Badajoz: Universidad de Extrema-

- Martos Nuñez, E. (2006). “Tuneado de libros: series, fan fiction, blogs y otras prácticas emergentes de lectura”, Ocnos, ${ }^{\circ}{ }^{2}$, págs. 63-78. Ediciones UCLM

- Mendoza Fillola, A. y Cerrillo Torremocha, P.C. (2003). Intertextos: aspectos sobre la recepción del discurso artístico, Ediciones Universidad Castilla La Mancha.

- Oakeshott, M. (2009). La Voz Del Aprendizaje Liberal. Buenos Aires/Madrid: Katz Editores, S.A.

- Van Dijk, Teun. A. 1983). La ciencia del texto. Barcelona: Paidós Comunicación. 